\title{
Correlation of Bone Mineral Parameters with Anthropometric Measurements and the Effect of Glucocorticoids on Bone Mineral Parameters in Congenital Adrenal Hyperplasia: Authors' Reply
}

\author{
Ramaswamy Ganesh ${ }^{1}$ • Natarajan Suresh ${ }^{1}$ - Lalitha Janakiraman ${ }^{1}$. \\ Karnam Ravikumar ${ }^{2}$
}

Received: 7 April 2016/Accepted: 9 May 2016/Published online: 24 May 2016

(C) Dr. K C Chaudhuri Foundation 2016

To the Editor: We thank the reader for the comments and providing us an opportunity to discuss further on our recently published article in the Indian Journal of Pediatrics [1]. Figures 1 and 2 represent the linear regression curves showing correlation of Total Body Less Head Bone Mineral Content (TBLH BMC) and bone mineral density (BMD) with height, as height has got a significant influence in bone area and BMC. We agree that we had not studied the impact of fat mass on BMD in this cohort. The values depicted in Table 3 show seemingly higher values of TBLH BMC and BMD and lumbar spine BMC and BMD in the group that received longer duration of steroids because the mean age of children in that group was older, which resulted in higher BMC and BMD than younger subjects. We could not use the Indian reference data for comparing bone mineral parameters published by Khadilkar AV et al. [2] as majority of children in this cohort were less than $5 \mathrm{y}$ of age and the reference values are available only for children more than $5 \mathrm{y}$ of age.

Ramaswamy Ganesh

ganeped79@rediffmail.com

1 Department of Pediatrics, Kanchi Kamakoti CHILDS Trust Hospital \& The CHILDS Trust Medical Research Foundation, 12-A, Nageswara Road, Nungambakkam, Chennai 600034, Tamil Nadu, India

2 Department of Pediatric Endocrinology, Kanchi Kamakoti CHILDS Trust Hospital \& The CHILDS Trust Medical Research Foundation, Nungambakkam, Chennai, Tamil Nadu, India
Compliance with Ethical Standards

Conflict of Interest None.

Source of Funding None.

\section{References}

1. Ganesh R, Suresh N, Janakiraman L, Ravikumar K. Correlation of bone mineral parameters with anthropometric measurements and the effect of glucocorticoids on bone mineral parameters in congenital adrenal hyperplasia. Indian J Pediatr. 2016;83: 126-30.

2. Khadilkar AV, Sanwalka NJ, Chiplonkar SA, Khadilkar VV, Mughal MZ. Normative data and percentile curves for dual energy X-ray absorptiometry in healthy Indian girls and boys aged 5-17 years. Bone. 2011;48:810-9. 